volved. It is a reasonable assumption that in all four fractions described here the labelled phos. phorus was present as a mono-ester.

Hokin and Hokin ${ }^{5}$ have obtained rapid labelling in phospholipid fractions which correspond neither to phosphatidic acid nor to the major phospholipids, and these authors produce evidence ${ }^{6}$ which appears to eliminate lysophosphatidic acid. Rapid labelling with phosphorus-32 of two unidentified phospholipids in mitochondria has recently been reported ${ }^{2}$.

The metabolic significance of these minor components of the phospholipids cannot be assessed at the moment, but it is clearly of importance that their chemistry be elucidated.

Russell Grimwade School of Biochemistry, F. D. Colurns University of Melbourne.

${ }^{1}$ Kennedy, E. P., J. Biol. Chem., 201, 399 (1953).

${ }^{2}$ Kennedy, E. P., and Weiss, S. B., J. Amer. Chem. Soc., 71, 250 (1955).

s Brockerhoff, H., and Ballou, C. E., J. Biol. Chem., 236, 1907 (1961). Wagner. H., Lissan, ̈̈., Hölze, J., and Hörhammer, L., J. Lipid Res., 3, 177 (1962).

4 Collins. F. D., and Shotlander, V. L., Biorhem. J., 79, 316 (1961). - Hokin, L. E., and Hokin, M. R., J. Biol. Chem., 233, 822 (1958).

- Pleringer, R. A., and Hokin, L. E., J. Biol. Chem., 237, 653 (1962)

$>$ De Luca, H. F., Garbus, J., Loomans, M. E., Strong, F. M., and Bloom, s., Fed. Proc., 21, 54 (1962).

\section{Incorporation of Molecular Oxygen into Trans-L-Epoxysuccinic Acid by Aspergillus fumigatus}

SnNCE its discovery in $1937^{1}$ in appreciable yields in culture filtrates of two filamentous fungi, only a handful of studies, mainly by Sakaguchi, appear to have been made on the mycological formation of trans-L-epoxysuccinic acid2. The mechanism of its biosynthesis has been studied by Nomura et al. ${ }^{2}$ using compounds labelled with carbon-14 to trace the origin of the carbon atoms.

An outgrowth of earlier studies in this laboratory ${ }^{2}$ was the idea that the epoxide oxygen atom in the trans-L-epoxysuccinate molecule might be unique in being derived from molecular oxygen. This appears to be the case, and the following sheds some light on the pathway of biosynthesis of this uncommon dibasic acid.

Shaken cultures of Aspergillus fumigatus mycelium were prepared as described previously ${ }^{2}$. The filtered mycelium, $5.6 \mathrm{~g}$ wet weight, was suspended in $200 \mathrm{ml}$. of 3 per cent glucose solution in a 2-1. gas-tight suction flask. The atmosphere in the flask was replaced with air containing 80 per cent oxygen labelled with oxygen-18, and the suspension was then shaken continuously for $87 \mathrm{~h}$ at $30^{\circ} \mathrm{C}$. The epoxysuccinic acid was extracted from the culture filtrate with diethyl ether, yield c. $500 \mathrm{mg}$. It was purified by silica-gel column chromatography ${ }^{3}$, and recrystallized from acetone-chloroform mixture. The crystals had the correct melting point for trans-L-epoxysuccinic acid $\left(181^{\circ} \mathrm{C}\right)$.

The oxygen isotopic composition of the pure acid was determined by the method of Rittenberg and Ponticorvo4. The results (Table 1) indicate that one atom of oxygen in the epoxysuccinate was derived from molecular oxygen (assuming no exchange reaction). Since four of the five oxygen atoms in the acid are contained in carboxyl groups, we conclude that only one atom is labelled and that it must be the epoxide oxygen.

At the moment it is not possible to identify the oxygenation reaction generating epoxysuccinate

\begin{tabular}{c|c|c|c} 
Exp. & \multicolumn{2}{c}{$\begin{array}{c}\text { Table 1 } \\
\text { Oxygen-18, } \\
\text { Atom \% excess in }\end{array}$} & $\begin{array}{c}\text { Percentage of oxyeen in } \\
\text { epoxysuccinate derived } \\
\text { from molecular oxygen }\end{array}$ \\
\cline { 2 - 3 } I & $\mathrm{O}_{2}$ & Epoxysuccinate & 1.87 \\
II & 5.466 & 1.086 & 21.52
\end{tabular}

because we have been unsuccessful in obtaining synthesis of this product in cell-free extracts of the mould. Nomura et al. ${ }^{2}$ showed that the carboxylcarbons of epoxysuccinate produced in the presence of ${ }^{14} \mathrm{CO}_{2}$ had the same specific radioactivity as the mean values for carbons 1 and 6 in the citric acid formed in the same system, and oxalacetic acid was postulated as a common precursor of both acids. We have found that epoxysuccinate is formed from malic, succinic or fumaric acid as the sole carbon source in suspensions of living mycelium. Based on the available facts we postulate the following reaction:

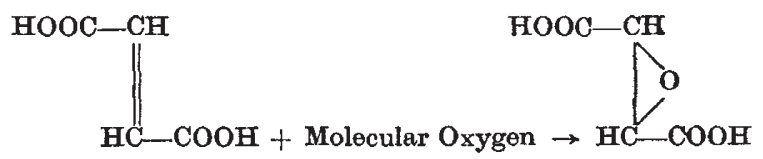

Fumaric acid

Trans-L-epoxysuccinie acid

Such an oxygenase would be different from those described in the literature ${ }^{5}$, and investigations directed towards its isolation are now being carried out.

This work was supported in part by grants from the National Science Foundation, the National Institutes of Health and the Office of Naval Research. Kō AIDA* J. W. Foster

Department of Microbiology,

University of Texas, Austin.

* Fulbright Fellow, 1960-61. Present address : Institute of Applied Microbiology, University of Tokyo, Tokyo, Japan.

Sakaguchi, K., Inoue, T., and Tada, S., J. Agric. Chem. Soc., Japan, $13,241(1937)$.

Sakaguchi, K., Inoue, T., and Tada, S., J. Agric. Chem. Soc. Japan, 14, 362 (1938). Sakaguchi, K., and Inoue, T., ibid., 14, 368, 1517 $(1938) ; 16,1015$ (1940). Nomura, G., Takahashi, H., and Saka. guchi, K., ibid., 28, 376 (1954). Birkinshaw, J. H., Bracken, A., and aistrick, H., Biochem. J., 39, 70 (1945).' Martin, W. K., and Foster, J. W., J. Bacteriol., 70, 405 (1955).

Colowick, S. D., and Kaplan, N. O., Methods in Enzymology, 8, 397 (Academic Press, 1957).

- Rittenberg, D., and Ponticorvo, L., Intern. J. App. Rad. Isotopes, 1, 208 (1956).

s Hayaishi, O., Proc. Intern. Symp. Enz. Chem., Toyko and Kyoto, 207 (1957). Mason, H. S., Adv. Enzymol., 19, 79 (Interselence, 1957).

\section{Oxidation of Vitamin $A_{1}$ and Vitamin $A_{2}$ Aldehydes to the Corresponding Acids by Enzymes from Pig and Rat Livers}

VrTAMrN A is stored in rat liver largely as its ester with small amounts of the alcohol, but is transported in the normal circulating blood in the latter form ${ }^{1}$. Although it was generally believed that the alcohol form is the more physiological state of the vitamin, since the work of Dowling and Wald ${ }^{2}$, it is being recognized that vitamin $A$ acid and not the alcohol may be nearer to the 'active vitamin A'. If this were to be so, it would be important to demonstrate that a mechanism exists in the rat for the production of vitamin $A$ acid from vitamin $A$ alcohol through the intermediate, the aldehyde. Regarding the formation of the aldehyde, it has been well established that tho alcohol dehydrogenase can bring about the conversion of vitamin A alcohol to retinene ${ }^{3}$. The presence of an 